\title{
Review of the book by Vyacheslav A. Ivannikov "A New Introduction to Psychological Thinking"
}

\author{
Eugene Aidman, \\ University of Sydney, Australia
}

First, a disclaimer: the book I am about to review is written by my mentor. Call me biased. I was fortunate enough to attend the lectures presented in this book. It was 35 years ago. I vividly remember how sought after was a good set of lecture notes from these lectures. Now this call has been answered by the author himself. It's been a long wait, and the new generations of Russian-speaking psychology students and instructors alike - are so much better off for it.

V.A. Ivannikov's "Bases of Psychology: A Lecture Course" (Moscow: Peter Publishing, 2010, 327pp.) is an unusual book. It is not a textbook, though it represents one of the most complete, long-running and influential lecture courses in introductory psychology known in Russian print. It is not a "state of the art" volume, either, despite offering highly original syntheses of the literature on advanced topics such as self-regulation and will-power.

The book builds on the foundations of Vygotsky's $(1978,2012)$ cultural-historical and Leontiev's (1978) activity theory to present an evolving conceptual framework that underpins the modern science of psychology. Whilst grown out of the well-known tradition approach (see Aidman, 1995; Peim, 2009; van der Veer, 2008), the lectures bear an unmistakable mark of the author's original take on the issues under consideration, with some lectures resembling more of an original research paper than a textbook chapter.

The book also follows another tradition - the one that is well established in the English print but rarely seen in Russian - the tradition of a systematic introductory text focused on supporting student thinking. The dominant impressions from Ivannikov's text are similar to those from Hilgard's (1953) Introduction to Psychology and its multiple subsequent editions. Each chapter articulates key constructs supporting contemporary understanding of human (and animal) 
behaviour and all major mental phenomena, with the coverage rivaling the most comprehensive of introductory texts. It then examines the method and the empirical substance that gave rise to this understanding and articulates the future steps in conceptual and empirical investigation that are likely to advance it. Likewise, the theoretical and empirical pitfalls awaiting students of psychology are equally well articulated, and the reader is left well equipped to avoid stepping on the same rakes twice when framing psychology-related questions and searching for their answers.

The book is a fresh attempt at presenting the often intimidating amount of Introductory Psychology material in a stimulating and thought-provoking fashion. The coverage of traditional introductory topics is comprehensive, and the logic of presenting each topic from both evolutionary and socio-cultural perspectives is well placed to help students and instructors to work through this critical intersection of the discipline: the interaction between Brain and Culture. The introduction of the conceptual distinction between MEANING and MECHANISM is extremely important in this context, and the text's balanced attention to the complementing roles of both is appealing.

Ivannikov's attempt at placing psychology in the context of biology and culture is not new (see Westen, 1996, for one of the many successful earlier attempts). But the text goes beyond the comfortable "a bit of both" approach in explaining cultural and biological determinants of human behaviour. Its emphasis on the mechanisms mediating the interaction between the brain and social context is thorough and convincing. The book's emphasis, not surprisingly, is on activity theory-derived principles of MEDIATED interaction (there is always a third factor such as prior experience, learning, etc.) and focusing on specific cognitive and motivational mechanisms of this mediation (such as action goals, motives, anticipation and operational constraints for execution).

The chapter sequence may seem unusual for a traditionalist. For example, chapters on cognitive processes (sensory and perception, thinking, attention and memory) are left to the very end of the sequence, preceded by a group of chapters on motivation and personality (including emotions, self-regulation/will-power and a whole lecture on the objects and subjective representation of needs). The chapters on the levels of consciousness are included into the front-end fundamentals of Part One of the book, along with lectures on the object and methods of the science, animal behavior and human action, conditioning, and higher mental functions. The front end is well supported by an evolutional analysis of behaviour and mental functioning, as a well as by a concise yet thorough exposition of key constructs of Leontiev's activity theory - activity, action and operation - driven by motives, goals and conditions, respectively.

Those who were, like me, privileged to see the "titans" of Russian psychological science in action, would attest to their wildly differing lecturing styles. Alexey $\mathrm{N}$. Leoneiev's lectures were inspiring yet almost threatening by their complexity. So were Eugene N. Sokolov's lectures. Alexander R. Luria’s lectures were mesmerszing by their unattainable clinical brilliance. Ivannikov's approach represented a quality disciple's interpretation: it was less spectacular but more systematic and perhaps 
more instructive - it managed to combine scholarly sophistication with accessible and engaging presentation style that was poised to keep the reader both enthused and well-directed.

All good introductory texts are pitched at intrinsic interests of students to spark and maintain their engagement. Hilgard's (1953) text appealed to those interested in developmental and clinical applications. Ivannikov's lectures emphasise evolutionary foundations of adaptive action and the mediating effects they exert on most mental processes. The author has taken some risk in presenting some cutting-edge research material which may be controversial or not fully confirmed (such as the segment on self-regulation and will-power). But it seems consistent with the text's aim explicated early in its Preface, which is to engage students in THINKING as psychologists and about psychology and its principles, rather than being swamped by its facts. The facts are accurately presented, too, but they become instrumental and hence do not have to be limited to the obvious or to the undisputed truths. Most crucially, the book charts important thinking habits required of anyone practicing the science or the discipline of psychology - with some clear guidance on how to build them.

One of the strengths of Ivannikov's text is that it achieves a balanced coverage of the subject matter, without sacrificing the presence of a strong and well-articulated author's position. Making the author's position explicit brings that personal touch that, sadly, often lacks in Introductory Psychology texts. This author's position is quite appealing and it has the capacity to stimulate students' thinking rather than setting them on the track of memorising the facts.

The text is written in a very articulate yet accessible, clear and engaging style. It will encourage students to think as they read on, which should suit most learning styles except the laziest. Most research examples are excellent. While the choice of examples is favouring the $20^{\text {th }}$ century Russian literature (which is to be expected), it is well balanced with the exposition of the wider world literature. What seems insufficient, though, is the referencing of the more recent research of the last decade or two. Updating these references would certainly strengthen the next incarnation of this book, especially if it ever grows into a formal textbook.

Ivannikov's parsimonious approach to illustrating the text is appealing. It makes the text look a little old-fashioned which I personally like. The text's visual design would perfectly suit a well-articulated, intrinsically motivated and text-tolerant reader. However, not all learners are like that, and some of the more visually-oriented learners may find the eye-catching features missing.

Overall, "Bases of Psychology" is a noteworthy addition to Introductory Psychology library. Its particular strength, in my opinion, is in its explicit focus on psychological THINKING, informed and inspired by the facts of the discipline, but not subdued by them. This focus is well complemented by the author's stimulating writing style, conceptual clarity and logical flow. And the author's position - ever present, witty an engaging - makes the text even more inviting for the reader. 


\section{References}

Aidman, E. V. (1995). Mozart of Psychology Re-introduced: Vygotsky as Revolutionary Scientist. Australian Journal of Psychology, 47 (2), 60.

Hilgard, E.R. (1953). Introduction to psychology. New York: Harcourt, Brace.

Leontiev, A.N. (1978). Activity, consciousness, and personality. Englewood Cliffs, NJ: Prentice Hall.

Peim, N. (2009). Activity theory and ontology. Educational Review, 61(2), 167-180. doi: $10.1080 / 00131910902846874$

van der Veer, R. (2008). Multiple readings of Vygotsky. The transformation of learning: Perspectives from activity theory, 20-37. Cambridge University Press. doi: 10.1017/ CBO9780511499937.004

Vygotsky, L. (2012). Thought and language. Eds. Hanfmann, E., Vakar, G. \& A. Kozulin. Camridge, MA: MIT press.

Vygotsky, L. (1978). Mind in Society. Camridge, MA: Harvard University Press.

Westen, D. (1996) Psychology: Mind, Brain and Culture. New York: Wiley. 